\title{
ABSCESSOS PERIODONTAIS: ATUAL CLASSIFICAÇÃO, DIAGNÓSTICO E TRATAMENTO
}

\author{
Milena Bubolz Zarnott ${ }^{1}$; Bruna Pacheco Haubert ${ }^{2}$; Camila Silveira Sfreddo ${ }^{3}$
}

\section{RESUMO}

Os abscessos periodontais caracterizam-se pelo acúmulo de secreção purulenta localizada dentro das paredes da bolsa periodontal, ocasionando um rápido colapso do tecido periodontal. A adequada classificação, diagnóstico e tratamento dessas lesões tem relevância significativa, pois representa a terceira maior causa de procura por tratamento odontológico de urgência. Este estudo tem por objetivo revisar narrativamente a literatura sobre os abscessos periodontais com ênfase em sua atual classificação, características clínicas para diagnóstico, etiologia e abordagem terapêutica. As lesões mais comuns de abscessos periodontais ocorrem em pacientes com periodontite, representando uma das principais causas de extração dentária durante a fase de manutenção periódica preventiva. O diagnóstico é realizado através dos sintomas relatados pelo paciente, sinais clínicos e radiográficos. O tratamento ocorre em duas fases, drenagem da lesão e, posteriormente, raspagem subgengival. Portanto, observou-se que a atual classificação simplificou a identificação dos abscessos periodontais, facilitando o diagnóstico e a comunicação entre os profissionais.

Palavras-chave: Doenças periodontais; Etiologia; Microbiologia; Terapia periodontal.

Eixo Temático: Atenção Integral e Promoção à Saúde (AIPS).

\section{INTRODUÇÃO}

De acordo com a atual Classificação das Doenças Periodontais, as lesões periodontais agudas são divididas em doenças periodontais necrosantes, abscessos periodontais e lesões endo-periodontais (CATON et al., 2018). Estas doenças estão entre as poucas condições em periodontia que necessitam de atendimento de

\footnotetext{
1 Milena Bubolz Zarnott - Universidade Franciscana. Email: milena.zarnott@ufn.edu.br

2 Bruna Pacheco Haubert - Universidade Franciscana. Email: b.haubert@ufn.edu.br

${ }^{3}$ Camila Silveira Sfreddo - Universidade Franciscana. Email: camila.sfreddo@ufn.edu.br
} 
urgência odontológica devido a sua sintomatologia dolorosa, resultado da rápida progressão, destruição dos tecidos periodontais e infecção (HERRERA et al., 2018). Dentre estas doenças, destaca-se o abscesso periodontal que se caracteriza pelo acúmulo de secreção purulenta localizada dentro das paredes da bolsa periodontal, ocasionando em um curto tempo, o colapso do tecido periodontal (HERERRA et al., 2018). Deste modo, o abscesso periodontal resulta em sinais e sintomas facilmente detectáveis no exame clínico do paciente, sendo considerado a terceira maior causa de procura por tratamento odontológico de urgência (HERERRA et al., 2018).

$\mathrm{Na}$ antiga classificação de 1999, os abscessos eram classificados em endodôntico, periodontal, gengival e pericoronal (HERRERA et al., 2000). Ainda, eram classificados quanto a sua localização, curso da lesão e número (HERRERA et al., 2014). Entretanto, essa classificação era de difícil aplicação prática devido a sua dificuldade em diferenciar os tipos de abscessos baseado simultaneamente na localização e etiologia (HERRERA et al., 2018). Além disso, o termo abscesso pericoronal foi raramente descrito na literatura e carece de evidência científica para sua classificação. Em 2018, foi realizada uma nova classificação para os abscessos periodontais, os quais foram divididos em abscessos periodontais em pacientes com periodontite e abscessos periodontais em pacientes sem periodontite (HERERRA et al., 2018). Deste modo, houve uma melhor definição dos diferentes tipos de abscessos e uma simplificação de sua classificação com intuito de facilitar o diagnóstico e manejo clínico (HERERRA et al., 2018).

A conduta para cada abscesso é diferente e, por isso, para o estabelecimento de um tratamento adequado é necessário classificar corretamente essas lesões (HERERRA et al., 2000). O diagnóstico é realizado por meio dos sintomas relatados pelo paciente, sinais observados no exame clínico, além de exames radiográficos complementares. Além disso, a realização de uma anamnese detalhada é de extrema importância, especialmente em casos de abscessos em pacientes não periodontais (HERRERA et al., 2018).

O conhecimento sobre a etiopatogenia, as características clínicas e a classificação dos abscessos periodontais permitem um correto diagnóstico e, consequentemente, escolha de uma abordagem terapêutica apropriada para cada 
caso (HERRERA et al., 2014). Embora estudos prévios tenham investigado sobre os abscessos periodontais, nenhum estudo revisou a literatura a partir da atual classificação destas lesões. Assim, o objetivo deste estudo é revisar narrativamente a literatura sobre os abscessos periodontais com ênfase na elucidação de sua atual classificação. Além disso, busca-se explorar as características clínicas para diagnóstico, sua etiologia e a terapia para manejo dessas lesões. Os achados desse estudo servirão de base para confecção de um manual de atendimento de urgências nas clínicas odontológicas da Universidade Franciscana, proporcionando capacitação entre os acadêmicos para atendimentos adequado e rápido dos indivíduos.

\section{METODOLOGIA}

Esta revisão narrativa de literatura incluiu estudos sobre abscessos periodontais em adultos com diferentes delineamentos metodológicos, incluindo outras revisões de literatura. Buscas eletrônicas foram realizadas na plataforma PubMed sem restrição de linguagem e de período de tempo. A estratégia de busca abaixo foi utilizada para busca dos artigos:

- (("periodontal abscess"[MeSH Major Topic] OR ("periodontal abscess"[MeSH Terms] OR ("periodontal"[All Fields] AND "abscess"[All Fields]) OR "periodontal abscess"[All Fields])) AND ("diagnosable"[All Fields] OR "diagnosi"[All Fields] OR "diagnosis"[MeSH Terms] OR "diagnosis"[All Fields] OR "diagnose"[All Fields] OR "diagnosed"[All Fields] OR "diagnoses"[All Fields] OR "diagnosing"[All Fields] OR "diagnosis"[MeSH Subheading]) AND ("adult"[MeSH Terms] OR "adult"[All Fields] OR "adults"[All Fields] OR "adult s"[All Fields])) NOT ("pericoronal"[All Fields] OR "pericoronitis"[MeSH Terms] OR "pericoronitis"[All Fields] OR (("pericoronal"[All Fields] OR "pericoronitis"[MeSH Terms] OR "pericoronitis"[All Fields]) AND ("abscess"[MeSH Terms] OR "abscess"[All Fields] OR "abscesses"[All Fields] OR "abscessation"[All Fields] OR "abscessed"[All Fields] OR "abscessing"[All Fields])))

Além disso, foi realizada a busca manual nas listas de referência dos artigos incluídos. Os artigos sobre classificações de 1999 e 2018 sobre Doenças Periodontais também foram selecionados com propósito de comparar as definições 
dos abscessos periodontais. Informações a respeito das características clínicas, etiologia, microbiologia, diagnóstico e tratamento foram extraídas dos artigos.

\section{RESULTADOS E DISCUSSÕES}

Ao total, a estratégia de busca gerou 331 artigos. De acordo com a atual classificação dos abscessos periodontais (CATON et al., 2018; HERRERA et al., 2018), estas lesões podem ser divididas em: abscessos periodontais em pacientes com periodontite (em uma bolsa periodontal pré-existente); e abscessos periodontais em pacientes sem periodontite (ausência de uma bolsa periodontal pré-existente como característica fundamental) (HERRERA et al., 2018). Os abscessos periodontais são mais comuns em pacientes com periodontite com maior prevalência em casos de periodontite não tratada, além de afetarem mais os dentes molares devido sua anatomia que favorece o acúmulo de biofilme dental (HERERRA et al., 2000).

O abscesso periodontal em pacientes com periodontite pode ocorrer em três diferentes situações: exacerbação de lesão crônica; e abscesso periodontal pósterapia (raspagem, cirurgia, antibiótico) (HERRERA et al., 2018). A etiologia da doença ocorre diferente em cada situação de doença que o paciente se encontra.

Exarcebação de lesão crônica:

a) Em casos de pacientes com periodontite não tratada (Fig. 1), pode ocorrer devido a uma exacerbação da doença periodontal crônica, onde a presença de bolsas profundas e tortuosas, assim como envolvimentos de furcas (Fig. 2) e defeitos verticais favorecem o fechamento marginal da bolsa que não consegue realizar a drenagem do abscesso periodontal (DELLO, 1985; HERERRA et al., 2018). Nos pacientes que se encontram em manutenção periodontal, o abscesso periodontal pode ocorrer devido a uma recidiva da doença, com período de agudização, impactação de corpo estranho como pedaços de suturas deixadas no interior da bolsa após a realização da técnica cirúrgica (HERERRA et al., 2018);

b) Em casos de recidiva de periodontite (FINE et al., 1994); 
c) Nos pacientes que se encontram em manutenção periodontal, o abcesso periodontal pode ocorrer devido a uma recidiva da doença, com período de agudização (HERRERA et al., 2018).

Após terapia periodontal:

a) O abscesso periodontal pode ocorrer devido a presença de restos de cálculo dental durante a realização de desbridamento subgengival, os quais podem ficar aprisionados em uma região mais profunda da bolsa (DELLO et al., 1985);

b) Impactação de corpo estranho como pedaços de suturas deixadas no interior da bolsa após a realização da técnica cirúrgica (HERERRA, 2018);

Utilização de antimicrobiano sistêmico sem 0 desbridamento subgengival profissional, o que acaba gerando uma superinfecção devido a uma alteração da microbiota (HELOVUO; PAUNIO, 1989; HELOVUO; HAKKARAINEN; PAUNIO, 1993; TOPOLL; LANGE; MULLER, 1990).

Figura 1 - Abscesso periodontal em paciente com periodontite não tratada.

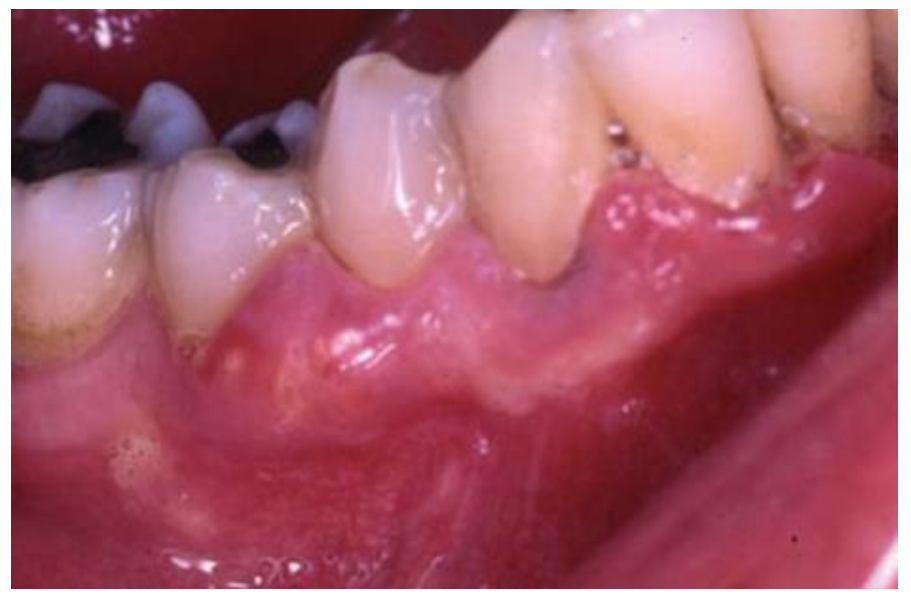

Fonte: HERRERA (2014, p. 152)

Figura 2 - Abscesso periodontal em paciente com periodontite com presença de envolvimento de furca. 


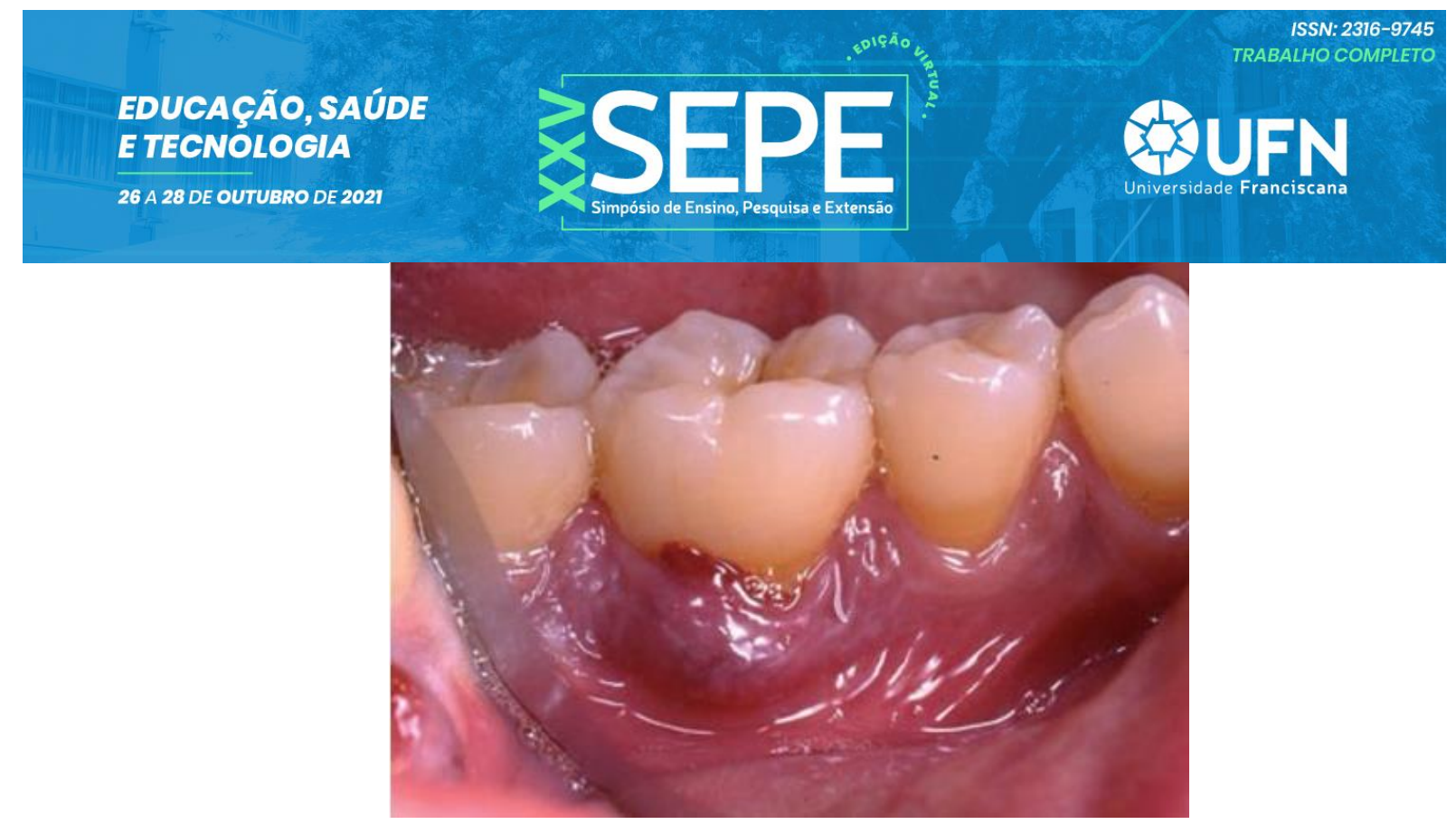

Fonte: HERRERA (2014, p. 151)

Os abscessos periodontais de pacientes saudáveis podem ser gerados pela impactação de um corpo estranho (HERRERA et al., 2018). Dentre os corpos estranhos mais comuns, destacam-se elástico ortodôntico, pedaço de dique de borracha, casca de milho de pipoca, pedaço de palito de dente, fragmento de unha para pacientes com hábito de roer unhas ou pedaço de fio dental (HERERRA et al., 2018).

Quanto a patogênese e histopatologia, a entrada das bactérias na bolsa periodontal pode ser o primeiro evento a iniciar um abscesso periodontal (DEWITT et al., 1985). O processo inflamatório inicia quando as células de defesa são atraídas pela liberação de fatores quimiotáxicos liberados pelas bactérias, em contrapartida, o organismo responde gerando uma destruição de tecido conjuntivo, encapsulando a infecção bacteriana que resulta em acúmulo de coleção purulenta (HERERRA et al., 2000).

Nos aspectos histológicos, foi encontrado inicialmente neutrófilos intactos ao redor de restos de tecidos moles e leucócitos destruídos, posteriormente, macrófagos se unem aos neutrófilos formando uma membrana. A taxa de destruição no abscesso dependerá do crescimento bacteriano, sua virulência e do pH do local, onde quando mais ácido maior será o poder das enzimas lisossômicas (HERERRA et al., 2000).

Em relação as características microbiológicas, os abscessos periodontais são polimicrobianos, no entanto poucos estudos demostram uma microbiota específica 
EDUCAÇÃO, SAÚDE

ETECNOLOGIA

26 A 28 DE OUTUBRO DE 2021

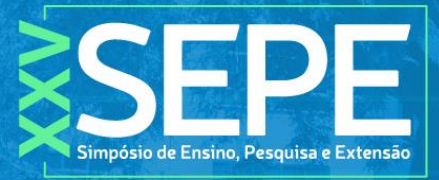

(HERRERA et al., 2014). Bactérias gram-negativas são as mais prevalentes, sendo as principais e comumente encontradas nos estudos as Porphyromonas Gengivalis, Prevotella intermedia e Fusobacterium nucleatum, porém, outras espécies podem estar presentes em menor quantidade (FINE, 1994; HERRERA et al., 2000). Sendo assim, nota-se que a microbiota encontrada é semelhante à da periodontite, havendo uma diferença em casos que o paciente utilizou antimicrobiano sem realizar o desbridamento mecânico subgengival, onde bactérias oportunistas como a Staphylococcus aureus sendo capazes de gerar uma superinfecção (HERERRA et al., 2000).

O diagnóstico dos abscessos periodontais é realizado através dos sintomas relatados pelo paciente, pelos sinais encontrados no exame clínico e características presentes no exame radiográfico (CHAN; TIEN, 2010; HAFSTROM et al., 1994; HERRERA et al., 2000; JARAMILLO et al., 2005). Os sintomas comumente relatados pelos pacientes, vão desde um leve desconforto até mesmo a uma dor intensa, dor na gengiva e sensibilidade do dente a palpação (HERRERA et al., 2014). Clinicamente, pode ser encontrado uma elevação ovóide na gengiva ao longo da parte lateral da raiz, porém, caso o abscesso seja mais profundo, esse sinal clínico pode não ser tão evidente, nesses casos, a região pode se apresentar avermelhada e com a presença de um edema difuso (HERRERA et al., 2014). Outros sinais frequentemente encontrados são a mobilidade dentária, edema, sangramento gengival espontâneo ou sob pressão, supuração à sondagem e bolsas periodontais profundas igual ou maiores que $6 \mathrm{~mm}$ (HERERRA et al., 2000). O exame radiográfico pode mostrar uma região normal, espaçamento do ligamento periodontal ou até mesmo uma perda óssea. O paciente pode apresentar comprometimento sistêmico como febre, linfoadenopatia, mal-estar e leucocitose em alguns casos mais graves (HERERRA et al., 2000).

O diagnóstico e tratamento precoce dos abscessos periodontais não somente traz benefícios para a saúde bucal do paciente, mas também para sua saúde sistêmica (HERRERA et al., 2014). A literatura reporta casos de disseminação dessa infecção odontogênica para outras partes do corpo como para pulmões, mama e joelho, foi observada em alguns estudos (HERERRA et al., 2000). 
O tratamento dos abscessos periodontais é realizado em duas etapas (LINDHE; LANGE; KARRING, 2008, cap. 22). Primeiramente, é realizado o tratamento da fase aguda da doença que consiste em drenagem da secreção purulenta, a qual pode ser feito por meio da bolsa periodontal utilizando sonda periodontal com movimentos pendulares em todos os sítios da bolsa. Para este procedimento de drenagem, o paciente deverá estar anestesiado. Nessa fase inicial, também é feita a remoção do corpo estranho caso esteja presente. Após o tratamento da fase aguda, cerca de uma semana depois, é realizado o desbridamento subgengival convencional. É importante que o desbridamento não seja feito durante a fase aguda, pois o tecido que está desorganizado apresenta alto potencial de regeneração e cicatrização (HERERRA et al., 2018).

Além dos procedimentos acima mencionados, é indicado o uso de analgésico para o controle da dor do paciente, assim como o uso de agente químico como a clorexidina $0,12 \%$ para controle do biofilme dental. O uso de antimicrobianos está indicado apenas quando o paciente apresentar um comprometimento sistêmico como febre, linfoadenopatia ou mal-estar (HERRERA et al., 2014).

\section{CONCLUSÃO}

O presente trabalho revisou a literatura sobre os abscessos periodontais com ênfase na sua atual classificação. Essa classificação é baseada nos fatores etiológicos envolvidos (pacientes com periodontite versus pacientes saudáveis). Os abscessos periodontais em pacientes com periodontite são as lesões mais comuns e são associadas à redução da drenagem de uma bolsa periodontal profunda. Eles normalmente causam destruição rápida do tecido, o que pode comprometer o prognóstico dos dentes, e representar uma das principais causas de extração dentária durante a fase de manutenção periódica preventiva.

O histórico odontológico do paciente é de suma importância para o diagnóstico, sendo fundamental ter conhecimento de tratamentos prévios, como periodontais, endodônticos e a ocorrência de abscessos anteriores. Ainda, anamnese detalhada é um fator essencial, especialmente em casos de abcessos em pacientes não periodontais. O exame físico intra-oral minucioso afim de buscar alteração de cor, volume e textura, bem como, alterações nos exames periodontais é 
fundamental para o diagnóstico dessas lesões.

Os estudos não trouxeram evidências científicas sobre uma forma de tratamento único para os abscessos periodontais, podendo ser realizado diferentes abordagens terapêuticas. Buscar conhecer melhor a microbiologia dos abscessos periodontais é fundamental para que os profissionais possam adotar uma conduta mais adequada para a doença, realizando um tratamento específico para cada caso. No geral, o tratamento em duas fases é preconizado, iniciando com a drenagem da lesão e, posteriormente, é realizada a raspagem subgengival.

\section{REFERÊNCIAS}

CATON et al. A new classification scheme for periodontal and peri-implant diseases and conditions - Introduction and key changes from the 1999 classification. J Clin Periodontol. v. 45 (Suppl 20);p. S1-S8. 2018 Disponível em: <https://pubmed.ncbi.nlm.nih.gov/29926489/>. Acesso em: 11 set. 2021.

CHAN, YK; TIEN, WS. Clinical parameters of periodontal abscess: a case series of 14 abscesses. Malays Dent J. v. 31; p. 6-7. 2010. Disponível em: <http://mymedr.afpm.org.my/publications/42530>. Acesso em: 21 set. 2021

DELLO, NM et al. The post-prophylaxis periodontal abscess: etiology and treatment. Int J Periodontics Restorative Dent. v. 5; p. 28-37. 1985. Disponível em: <https://pubmed.ncbi.nlm.nih.gov/3888898/>. Acesso em: 22 set. 2021

DEWITT et al., The acute periodontal abscess: microbial penetration of the soft tissue wall. Int J Periodontics Restorative Dent. v. 5; p. 38-51. 1985. Disponível em: <https://pubmed.ncbi.nlm.nih.gov/3888899/>. Acesso em: 21 set. 2021.

FINE, DH. Microbial identification and antibiotic sensitivity testing, an aid for patients refractory to periodontal therapy: a report of 3 cases. J Clin Periodontol. v. 21; p. 98-106. 1994. Disponível em: <https://pubmed.ncbi.nlm.nih.gov/8144740/>. Acesso em: 22 set. 2021. 
HAFSTROM, CA et al. Effect of treatment on some periodontopathogens and their antibody levels in periodontal abscesses. J Clin Periodontol. v. 65; p.1022-1028. 1994. Disponível em: <https://pubmed.ncbi.nlm.nih.gov/7853125/>. Acesso em: 22 set. 2021.

HELOVUO, H; HAKKARAINEN, K; PAUNIO, K. Changes in the prevalence of subgingival enteric rods, staphylococci and yeasts after treatment with penicillin and erythromycin. Oral Microbiol Immunol. v. 8; p. 75-79. 1993. Disponível em: <https://pubmed.ncbi.nlm.nih.gov/8355988/>. Acesso em: 21 set. 2021.

HELOVUO, H; PAUNIO, K. Effects of penicillin and erythromycin on the clinical parameters of the periodontium. J Clin Periodontol. v. 60; p. 467-472. 1989. Disponível em: <https://pubmed.ncbi.nlm.nih.gov/2600754/>. Acesso em: 21 set. 2021.

HERRERA, D. et al. Acute periodontal lesions. Journal of Clinical Periodontology 2000, v. 65; p. 149-177. 2014. Disponível em: <https://pubmed.ncbi.nlm.nih.gov/24738591/>. Acesso em: 11 set. 2021.

HERRERA, D. et al. Acute periodontal lesions. Journal of Clinical Periodontology 2000, v. 65; p. 151-152. 2014. Disponível em: <https://pubmed.ncbi.nlm.nih.gov/24738591/>. Acesso em: 11 set. 2021.

HERRERA, D. et al. Acute periodontal lesions (periodontal abscesses and necrotizing periodontal diseases) and endo-periodontal lesions. Journal of Clinical Periodontology. Supplement, v. 45; n. 20; p. S78-S94. 2018. Disponível em: <https://pubmed.ncbi.nlm.nih.gov/29926942/>. Acesso em: 11 set. 2021.

HERRERA, D. et al. The periodontal abscess: a review. Journal of Clinical Periodontology 2000, v. 27; p. 377-386. 2000. Disponível em: <https://pubmed.ncbi.nlm.nih.gov/10883866/>. Acesso em: 11 set. 2021. 
HERRERA, D. et al. The periodontal abscess (I). Clinical and microbiological findings. Journal of Clinical Periodontology 2000, v. 27; p. 387-394. 2000. Disponível em: <https://pubmed.ncbi.nlm.nih.gov/10883867/>. Acesso em: 11 set. 2021.

JARAMILLO, A. et al. Clinical and microbiological characterization of periodontal abscesses. J Clin Periodontol. v. 32; p. 1213-1218. 2005. Disponível em: <https://pubmed.ncbi.nlm.nih.gov/16268997/>. Acesso em: 22 set. 2021.

LINDHE, J; LANGE, NP; KARRING, T; Tratado de periodontia clínica e implantodontia oral. 5a edição. Rio de Janeiro. Editora Guanabara Koogan S/A, 2010.

TOPOLL, HH; LANGE, DE; MULLER, RF. Multiple periodontal abscesses after systemic antibiotic therapy. J Clin Periodontol. v. 17; p. 268-272. 1990. Disponível em: <https://pubmed.ncbi.nlm.nih.gov/2347952/>. Acesso em: 21 set. 2021. 